Ageing and Society

A Lloyd, E Haraldsdottir, S Murray, M Kendall and B McCormack.

\title{
Stories from people living with frailty
}

\section{Abstract}

We describe the findings of a qualitative longitudinal interview study of a group of initially community dwelling frail older people, their informal and formal carers. We used a narrative approach to explore the role that narrative may have for people living with frailty. This has been less explored comparative to the experiences of those living with chronic illness. The frail older people told stories of their experiences that revealed three distinct shapes or typologies. These were either stable, unbalancing or overwhelmed and related to how the person managed to adapt to increasing challenges and losses and to reintegrate their sense of self into a cohesive narrative. Each is illustrated by an individual case story. Frailty is described as both biographically anticipated yet potentially biographically disruptive as older people may struggle to make sense of their circumstances without a clear single causative factor. Findings are discussed in relation to biographical disruption and reconstruction in chronic illness and the rhetoric around 'successful ageing'. We conclude by drawing attention to the complex individual and social factors that contribute to the experience of living with frailty in later life.

Keywords:

Narratives, Frailty, Older People, Qualitative Research, Longitudinal Research 


\section{Introduction}

Frailty is a condition that involves poor health outcomes, increased vulnerability and comorbidity (Clegg et al., 2013). More people reach the end of life following a period of frailty than organ failure or cancer and do so after a longer time frame that can extend to years (Zheng et al., 2013). The experience of frailty for older people extends beyond declining health and physical well-being to encompass different dimensions of their well-being to include psychological and social functioning (Puts et al., 2009, Warmoth et al., 2016). Considering these different aspects of well-being is thus vital for understanding the overall experience. Well-being is a conceptually complex term with competing definitions, however may be considered here as the degree of personal comfort, or defined as 'the balance point between an individual's resource pool and the challenges faced' (Dodge et al., 2012 p:230).

A longitudinal study of the experience of frailty describes it as a state of ambiguity and imbalance with participants described as existing in the spaces between dependence and independence, between health care and social care and between active living and clinically recognized dying, with functional and social losses (Nicholson et al., 2012). Physical losses brought a sense of change for older people living with frailty, both in how they saw themselves and in how others saw them. For some this was experienced gradually but for others it was more sudden following specific events. Frail older people were described as continually working to construct their identity and maintain control over their changing physical and social circumstances by creatively using everyday routines and rituals to root themselves to their worlds and create balance. Analyses of qualitative and quantitative data 
collected over one year which considered interactions between different dimensions of wellbeing, highlighted how older adults' experiences of health and mobility changes were related to attempts to maintain control over life in other ways (Lloyd and Cameron, 2005, Lloyd et al., 2011, Lloyd et al., 2014a). Mental health difficulties were associated with socio-economic difficulties and restricted physical capacity, compromising the ability to leave the house as desired. The accounts that some of the older people gave of death and dying focused on their wishes to determine one's own death, making legal and financial preparations, and fears of burdening others. Others avoided contemplating the future either by taking a religious or spiritual view or by adopting a stoical stance. A further longitudinal, qualitative study with 34 adults over 70 who received daily support, revealed attempts to maintain supportive social networks of family and friends, which influenced their future care decisions (Lloyd et al., 2014a). Despite finding end-of-life discussions difficult, older people described varying degrees of having made their preferences clear and having planned accordingly. Some, however, had made no plans as they perceived that they had no control over their future. Participants also described existential challenges in the struggle to live with a precarious existence, and challenges in maintaining dignity while receiving health and social care. Lloyd describes the interaction between physical and psychological difficulties as the older people attempted to cope and adapt in the face of their changing circumstances, contributing to challenges to their understandings of the self. Further qualitative research also outlines the difficulties older people describe in accepting the help that they need as loss of independence was associated with fears of being a burden on others (Lloyd-Williams et al., 2007).

\section{Narratives}


An alternative way of considering how people experience and manage change over time in different aspects of life is through personal narratives, which can be used to help us to organise and construct meaning in our experiences (Murray and Chamberlain, 1999). Illness narratives have begun 'emerging in the public domain' (Bingley et al., 2006) and illness experiences appear to be readily expressed in narrative form (Elliot, 2005). Applying a narrative approach to investigating experiences of illness and death has also gained academic interest, with disciplines such as medicine and psychology employing the method for investigating health and illness. Some have researched the storied nature of traumatic illness experiences and HIV (Crossley, 1999), the experience of cancer (Frank, 2013) or the palliative care needs of those with lung cancer and heart disease (Murray et al., 2002). Others have found that a narrative form is frequently taken to express the experience of chronic illness and can represent a biographical disruption (Bury, 1982). This involves disruption of the taken-for-granted aspects of the physical body, of daily life, and of relationships with the self and others where the person experiences a shift from their normal expected life trajectory that undermines self-identity (Bury, 1982). Furthermore, people may cope with chronic illness by attempting to reconstruct a cohesive narrative (Williams, 1984). The theory of biographical disruption as a response to chronic illness may, however, underplay the role of age and stage in the life course, given that much of this early work was carried out with younger adults where chronic illness is unusual (Lawton, 2002).

The aim of this study was to understand the changing experiences of frail older people through the stories that they told. We used a narrative approach to develop an in-depth insight into how frail older people make sense of their lives whilst facing reduced physical function, increasing dependence, illness and death. The role that narratives and sense of self 
may have for people living with frailty, has been less explored comparative to the experiences of those living with chronic illness. Narrative gerontology considers 'life as a story', in that stories underpin people's thoughts actions and interpretations (De Medeiros, 2013 p32).

Many definitions of frailty exist. However the definition that best fits this narrative study is of frailty as a socially constructed and a dynamic process involving the person and their broad social environment, emerging at the tipping point between social and functional dependence and independence (Kaufman, 1994).

\section{Methods}

Participants over 75 years with moderate or severe frailty, according to the Clinical Frailty Scale (Rockwood et al., 2005), and a Mini-Mental State Examination (MMSE) (Folstein et al., 1975) score over 23 , showing that they had minimal or no cognitive impairment, were recruited from a medical day hospital. Sampling was purposive to reflect the gender balance, co-habitation status, and demographics of those over the age of 75 (ONS 2006). Participants were invited to nominate an informal carer and also a health or social care professional who was most involved in their care. Individual or joint interviews, with the informal carer, of between 35 and 120 minutes were carried out up to three times over a mean period of 18 months. Eight weekly telephone contact with participants allowed on-going circumstances to be considered in an attempt to capture change. Written consent was obtained from each participant and verbal consent was obtained at follow-up interviews. Anonymity of the participants was ensured by assigning each a unique identifying number and removing all 
names of people and places in the transcripts. Pseudonyms were chosen randomly to present the findings.

Analysis was undertaken using the voice-centred relational method (VCRM) where emphasis is on reflexively, attending to the overall plot, then hearing the voice and story of the individual in relation to their self, their social world and in terms of their broader history and society, through discrete readings of each transcript. The method also includes a built-in reflexive component, where the researcher is required to explore their own reactions and biases to the interview. The analyses were plotted visually using the themes from each of the four analytical readings at each time point, to consider if or how issues changed, remained stable, or inter-related and overlapped with links drawn between time points. This enabled the form of the stories to emerge, allowing change over time across the different dimensions of well-being to be understood and case studies to be compiled. The stories were plotted graphically by different dimensions of well-being to evaluate the narrative form that the stories took. Subsequent comparison across time and between case studies allowed similarities and differences in the stories to emerge. Further details of the methods, data analysis and graphical representations of the narratives, ethical approval and quality assurance, including reporting in line with COREQ guidelines for qualitative research, are reported elsewhere (Lloyd et al., 2016). Data collection and analysis was undertaken by the lead researcher and was subsequently discussed and interpreted every eight weeks with the other members of the research team.

\section{Results}


13 frail older people (age range 76-92), 13 linked carers and 8 professional carers were recruited. 54 patient and carer interviews, 14 of which were joint with a carer were carried out.

Three distinct forms or patterns of change over time were discernible. The first group of five participants recounted stories that were stable and told of coping where areas of physical, psychological, social and existential well-being were maintained or changed little over time. The second group of five participants told stories that were unbalancing and began to reflect more of a struggle as well-being in different dimensions fluctuated over time. The final three participants told stories of becoming overwhelmed by their difficulties with a sharper decline in the different dimensions of well-being, reaching a tipping point ultimately before death. It may be that together, these story shapes can form a longer period of decline towards death, however people did die whilst living within each of the narrative types. Each of the three distinct narratives will be outlined and illustrated via the following detailed case stories of three participants told from the perspective of the researcher who carried out the interviews and analysis.

\section{Narratives of stability and coping}

The older people whose stories reflected stability and coping experienced physical decline over the course of the study yet managed to maintain their sense of self. While they experienced losses in the other dimensions of their lives, they were able to adapt to and make sense of their circumstances. These were stories of restitution, even towards the end of life, and can be illustrated in the example of Mrs Brown. 
Mrs Brown's Story:

The story began with Mrs Brown experiencing a period of instability following a hip operation. Recurrent dislocation and a subsequent antibiotic resistant bacterial infection necessitated long stays in hospital and then a protracted period bedridden at home, with episodic confusion from the effects of analgesic medications and a painful pressure sore on her heel. Her daughter, Mrs Durant visited daily and I interviewed them together. Mother and daughter wished to put this period beyond them and move on from. Mrs Brown's mobility had reduced in consequence, yet she had managed to come to terms with this and had adapted to this new normal. Mrs Brown did not question her circumstances claiming that she was contented and had accepted her degree of physical disability. However, Mrs Brown had had many years to adapt to reduced physical capacity having been diagnosed with osteoarthritis 40 years previously. She had regular carers now and was visited 3 times daily and had developed a rapport and friendship with most. Mrs Brown also had found a way to adapt to her frequently voiced complaint of evening care visits (titled a 'tuck in') to assist with getting ready for bed, at $8 \mathrm{pm}$ in the evening and sometimes earlier.

Mrs B: Well they are coming quite early in the evening, but I don't go to my bed, they get me ready and I just sit and watch the television in my bedroom and go to my bed when I feel like it'.

Mrs Brown retained a strong, autonomous sense of self that only faltered in relation to hospital stays that she felt she had no control over. Having been traumatised by the events of recent years she wished to avoid more hospital stays.

Researcher: 'And your thoughts about having to go [to hospital]?' 
Mrs B: 'No no, not. I mean once they get a hold of you in there.' 'Well three times I've been there and I mean it's three months every time I go.'

Mrs Brown also expressed her refusal to go into a nursing home

Mrs D: Oh aye I know, I know but you're, but she more or less just told them there's no way I'm going in a home and ( $\mathrm{mm} \mathrm{hm)}$

Mrs B: You cannae make me

Mrs D: And that's it she just was determined and that was it

Mrs B: Aye, no way I wouldnae be here if I'd been put in a home ( $\mathrm{mm} \mathrm{hm}$ )

Mrs Brown was now focusing on living day to day by focusing on visits from friends and family, agreeing with her daughter that she was contented, her only expressed wish being to return to the day centre having lost her place due to the protracted hospital stays and remaining on the 6-month waiting list.

Mrs D: 'she's very content, everybody says that she's very content, you know, being in The house it disnae bother her, she can watch her telly, she can do her crosswords. She's been knitting all these squares for the church and she's now doing squares for the [day centre] just sitting knitting so I mean she just does what she can and that's it.' Mrs B: 'But I mean it's far better than in a hospital isn't it, oh definitely. It disnae bother me.'

Mrs B: 'Quite happy. once I get going back to the [day centre]'

Over the following months she did return to the day centre where she was involved in the regular social events including knitting for their charity drives. She maintained her close relationship with her daughter and with friends and neighbours who visited.

Eventually Mrs Brown began to suffer with increasing pain in her hip, but surgical intervention had been ruled out due to vascular complications. She was also experiencing tiredness, 
shortness of breath and rectal bleeding. Although she had attended hospital for initial investigations she had decided to decline the planned follow up investigations. Together with the GP who, having visited every couple of months, now visited every couple of weeks, and her daughter, Mrs Brown had decided to decline further investigations or interventions as Mrs Durant explained.

Mrs D: 'I mean, she got out the hospital and she just... They wanted to do it again, the test, and she just said no, there was no way and the doctor came in the next day and he says "no, no".'

However, the reasons given were a wish to avoid any potential in-patient stays and to maintain her place at the day centre. A nursing home was regarded by Mrs Brown like many others in this study as almost akin to a terminal diagnosis. The mere name conjured a shudder and in Mrs Brown's words -

Mrs B: 'I would not be here if I had had to go into a nursing home'. It was not something that she would consider but neither did she speak much about it.

Mrs B: 'As long as I am able to be in this house, I'll be quite happy.' What Mrs Brown planned was to focus on symptomatic control in her own home. The decision to forego curative treatment indicated that, with the GP's support, she was moving to a supportive and palliative care route, despite no discussion of dying or of the term palliative care. Ultimately Mrs Brown accepted her current circumstances, attributing her situation to clear medical causes of osteoarthritis and peripheral vascular disease. She had had many years to integrate disability and physical decline into who she was and her overall story, while keeping a distinct separation from self as cause. Her sense of self never seemed in crisis having restored a feeling of normality following the chaos of recent years. She was existentially comfortable as long as she had her daughter and could attend the day centre. Crucial to Mrs. 
Brown's well-being was her connection with the outside world enabled by the strong social network and involvement in her community. Mrs Durant revealed Mrs Brown's attempts to show reciprocal care by offering to go to respite care to allow her daughter to go on holiday.

'Oh, she's fine! It's more... it's me that's... eh, I mean, she keeps saying to us "you'll need to have a holiday, you'll need to have a holiday"'

Further, the close bond with her daughter was vital in maintaining her life choices and remained a life constant that was cherished. As her daughter recounted

'She's content really. She's got ...well she has a lot of people coming in and out and she takes an interest in what everybody's doing and she likes, you know her day centre and she likes just getting out eh at the weekend, if we...you know, we take her out maybe once twice, you know, at the weekend and she just loves it, she loves to get out.'

\section{Narratives of struggle and unbalancing}

The older people whose stories reflected struggle and increasing unbalance experienced gentle physical decline over the course of the study and their social connections similarly reduced with family relationships often becoming strained. While they had a degree of community engagement and support networks, it was to a lesser extent than the participants whose narrative remained stable. While initially revealing hope for improvement in their lives and attaining a temporary restitution or maintaining an even keel, they expressed ill ease with their circumstances as time progressed. This was highlighted by varying degrees of fear and anxiety over what the future may hold. The gradual erosion of their sense of self marked the beginnings of existential suffering, as each felt a threat to a deeply valued aspect of their lives which they struggled to maintain. These narratives can be illustrated by the story of George. 
George's story:

George lived in sheltered housing with his wife Alice, who also lived with the disability of a chronic illness, George having taken full care of her for many years until his own illness prevented him from continuing. Both were animated and joked regularly. Alice told me the story of their lives and their current world focused on family and friends.

Alice: 'we've not got a lot of pals to visit, [researcher], I never, you know. So the laddies and lassies are out and in, out and in. The neighbours pop in from time to time and everybody's aye popping in, one or the other neighbours.

They also maintained a strong sense of connection to the local community.

Alice: 'His dad, up in the photos, his dad and granddad wis born in [area] and they lived for 90 years in [area] and I worked in Stockbridge right over there and we've lived our life in [area].'

They had no children and had formed an extremely close bond with their care worker, Irina, joking with me when I arrived about how they wanted to adopt her. Irina visibly reciprocated their affections and regularly accompanied and helped Alice to go out in their local area in her own time. George had declined physically over recent years, however the couple attributed his circumstances to a fall which had resulted in ongoing hip pain. George's sense of himself as physically strong and capable endured and he hoped regular physiotherapy would enable him to leave his home under his own steam. That this George was not the real George was something they wanted to impress on me.

Alice: 'I can't believe he's like that, a fitter man you couldn't find, I mean even when he retired.'

George: 'I was telling [researcher] I played football nearly every day.' 
Although both George and Alice wished to go out more, Irina and the other carers that visited offered a link to the outside world that the couple enjoyed. George and Alice clearly identified with their selves collectively as a couple both regularly using 'we' when they could have used 'l', 'he' or 'you'.

Alice: we're quite contented souls, ken what I mean? We don't have a great...

George: Och aye, as the weather gets better we're hoping to get out a bit more.

Alice: ... and great expectations, we're just very happy to be here (uh-huh), together.

Together they conveyed a sense of being in control of their world and in trying to accept their circumstances.

Alice: 'we didn't want [carers and help in the home] and he particularly didn't want [carers and help in the home] but it was a big step to do that and we accept now we can't do without the help so don't be proud, take the help and make your life easier and you've got time to sit and enjoy each other's company'.

They retained autonomy through their voices, stating what they did and did not want, as their bodies struggled to function. They hoped to continue outings to events such as theatre matinees, but their confidence had been dented by a recent taxi driver who had got cross at the bloody wheelchair. George and Alice worried about how they may 'end up' specifically after seeing people in hospital with dementia.

Alice: 'what you think is this a view into the future and what's going to happen to me and that's what upset me more than anything and you know am I going to end up like that'.

They also rejected the suggestion of nursing homes.

Alice: 'The warden said that we may want to go into a home, but we DO. NOT. WANT.

TO. DO. THAT' 
Alice stated with George nodding and agreeing

George: 'Oh that's a last resort.'

Staying together in their own home was frequently voiced and seemed vital to at an existential level them as it gave their lives meaning, purpose and continuity with their past with George nodding vigorously to Alice's statement.

Alice: 'We want to stay in my own home, we do, we want to stay in our own home'. They wanted to take each day at a time, to address George's pain and to regain some mobility.

In the months that followed George was found to have a severely degenerated hip joint, despite months of being given reassurance to the contrary. He had undergone a total hip replacement and when I met them again, I found them to be more subdued, their joviality now absent with Alice proclaiming 'Oh, it's been a hell of a year'.

George: 'So what's that, a week in the Royal...'

Alice: 'A week in the Royal and then four...'

George: '...and then four weeks - was it four weeks in the...?'

Alice: 'It was three weeks in the... nearly four in the...'

George: 'Three weeks in the Royal Victoria.'

The couple's trust in health care professionals was further dented following George's recent inpatient experience as George told of many episodes of poor nursing care including the neglect of a distressed fellow patient.

George: 'the male nurse completely and ehm he went back to his laughing and joking with the nurses ( $\mathrm{mm} \mathrm{hm}$ ) completely ignored this old man'.

A return to hospital for either of them was dreaded.'

Alice: 'you're home now, thank god. You don't want to be going back again either.' 
George's still hoped to regain his mobility and spoke with frustration about this desire yet did not seem to accept that he may still need walking aids or may not return to a capacity of recent years.

George: 'And I'd like to go out walking. Unaided. Unaided!'

George and Alice both reiterated again that this was not LIKE George. He was strong, stoical, and capable. George seemed ashamed of his level of disability and while he now focused on his new medical regime for his Parkinson's disease he did not offer this disease as a reason for physical decline. His circumstances just did not fit with his sense of who he was.

Alice: 'Before this all happened to him, he was a big strong fellow, you know. So that's stood you in good stead. It's all those plates of soup your mother flung down your throat and I flung down your throat.'

George: 'Aye, strong... well, the upper torso's strong, that's it, strong arms and everything else.'

He retained hopes on further rounds of physiotherapy to improve his mobility despite having been formally discharged from the day hospital.

George: 'So I'm waiting on word... I think I'll get word that I've to attend the day centre for physiotherapy again..'

Alice felt that George missed male company which was now confined to his ambulance trips to the day hospital with the male drivers, who would collect George first and drop him off last, enabling him to spend 2 or more hours seeing the world go by and chatting.

By the final interview a degree of hopelessness and powerlessness crept into George and Alice's talk. This was evident in how they no longer planned to take trips to the theatre and Alice took comfort in preferring to not leave their flat. 
Alice: 'Aye, to be honest, [name of interviewer], I've got to psyche myself up to go out, you know.'

Their previous capacity to control their world via their voice since their physical selves were declining seemed threatened as they felt powerless to influence their future.

Alice: 'If they make decisions you've got to agree with them'

Although George and Alice thought of the future, at no time did they talk of death instead relaying an increasing fear of moving to a nursing home. This was strongly resisted, and Alice talked of visiting people in nursing homes to explain their dread.

Alice: 'Well we'd have to say the preconceived ideas we've got about nursing homes, it frightens the life out of us. I've just got a horror of it, [interviewer], I've got a real horror of it, both of us.'

George nodded vigorously. Although the couple had initially adapted to their circumstances, in the face of a diminished capacity to influence their world through their voiced insistences, they began to lose their optimism and turned inwards from the outside world. Neither George nor Alice voiced consideration of their death. The future events that they feared were of developing dementia or of a move to a nursing home; fates worse than death that signified the end of their story.

Alice: 'Oh the future, we've got no future, it's in other people's hands now we know that.'

Their lives seemed precariously balanced on a precipice where existential comfort was garnered from staying together in the confines of their small home, propped up by the moral and physical support of Irina. I feared for them that the smallest issue would force them out of their house, into a care home where I felt they would existentially struggle. Our final meeting ended with Alice showing me a photo of her and George when they were young, 
beaming and smiling out of the frame, their youthful selves looking to their future. It struck me as a poignant gesture that acted as a coda summing up the very essence of their story of their life together in sad contrast to their fears for the future.

\section{Narratives of becoming overwhelmed.}

Broadly the overwhelmed narrative tells of physical and functional decline, involving worsening of symptoms such as pain, instability and fatigue and regular emergency hospital admissions, which occurred gradually although steepening towards death. Social losses mirrored physical decline. Psychological suffering in the form of depressive symptoms and anxiety was closely followed by existential suffering. A tipping point is reached where an important value that can bolster the older person's sense of self is lost and the older person gives up. Their existential death was the final loss which accrued before physical death. This narrative may be illustrated by the story of Mrs Howie.

Mrs Howie's story:

Mrs Howie was embedded in the community where she had lived for 20 years, managing daily outings on foot and on local transport into the city centre until recently. Clearly very sociable and interested in people and in the world around she felt lonely with her increased isolation.

Mrs H: 'I talk to the walls as if they're all my best friends, what else can I do?'

She relied on her daughter, Hazel, for social contact and for help with the ever-increasingly occurring emergencies from diabetic instability to falls, this relationship coming under stain.

Hazel: 'I just feel that she has become SO dependent $(\mathrm{mm} \mathrm{hm})$ that there are some days that I feel that I actually resent her. $(\mathrm{mm} \mathrm{hm})$ And the way things have 
been going recently (yes) so that's one of these things that not again, type of thing you know.'

Mrs Howie had experienced many emergency hospital admissions, and over the 8 months of the study was admitted to 3 different hospitals staying for several months in each. The subsequent immobility of the hospital stays and isolation in a single room due to methicillinresistant staphylococcus aureus infection exacerbated her mobility problems.

Describing her stress during this time, Hazel sought solutions in terms of practical help and in seeking information, but felt unsupported by health care services.

Hazel: 'I've had to find everything out by myself. Let's be honest. (OK) I really find that you know, there is absolutely nothing, even if the GP would come and check how mum was, I mean one of them from the practice actually said to her 'I don't know how you keep living in a flat you should be in sheltered housing' (uh huh) and wasn't very helpful (uh huh). And it would have been more helpful had he said, well, have you thought about and we can give you information or how to get information'

While Mrs Howie was in hospital a place in a sheltered housing complex became available. It was nearer Hazel's home thus she decided to take the place even though Mrs Howie had not seen it or agreed to the move. Her family had gone to great lengths to decorate the new home and make it familiar to Mrs Howie and a package of care was put in place with carers visiting 4 times per day as well as a district nurse. This transition was difficult for Mrs Howie and she attempted to adjust by trying to convey a degree of self-reliance in undertaking small self-care tasks

Mrs H: 'When the carer comes in we go through to the bathroom if I'm getting a wash she washes me all. We've two facecloths, we've one that, just for my face and hands 
and that and I have one that I keep for washing all the other parts. And then if it's dirtied at all I wash it through there myself and make sure it's clean, hang it up and just leave it there and she gets it the next morning. It might be damp but at least it's clean again, it is.'

She was also keen to stress that this assistance was new and not consistent with how she had been before.

Mrs H: 'Only since I've come out of the hospital there. I never had any help before, nobody helped me before it's only since I've come out of the hospital and came straight here that I've had the help, I'd no help before that, I didn't, no help whatsoever.'

Mrs Howie also made efforts with the care staff Mrs H: 'Well everybody that comes in I make myself sociable with them, I do.'

She remained, however, very reluctant to socialise in the complex despite expressing her loneliness.

Researcher: 'What do you think would help with your loneliness do you think, what do you think could happen that might help that?'

Mrs H: 'I don't know.'

Researcher: 'Getting help to go round [to the day room]?'

Mrs H: I'm one of these people that it doesn't really, I'm not fussed, I'm quite happy with my own company, I'm not one that's got to have somebody. I've got my telly if I want it it goes on.'

Mrs Howie missed the area that she used to live in and hoped that her old neighbour would visit, as he phoned daily and promised to come when he could work out the double bus trips. 
Mrs H: 'I think you get used to some place and my wee next door neighbour he was Wee bachelor and he was at sea all his life and then when he came home he used to say to me "Are you making any soup?" And I made the soup and I always, I kept him going in soup for his lunch. I made a different soup every week for him. He still phones me, he's supposed to come and see me but he doesn't know how to get from [Place] to here.'

A further issue that Mrs Howie struggled with was that she was proud to have kept the financial books for her son and had done for some years yet he appeared to be suddenly doing them himself.

Mrs H: "I did book keeping yeah. His father was still alive when he started the business and he said to his dad "I know who I'm going to get to do my books", he says "I've watched my mother", he says "and I'm going to have my mother doing my books", and I've done them for the last ten years.'

However, Mrs Howie looked to the future with the hope that she may regain the mobility to leave the flat.

Researcher: 'So have you any thoughts for the next wee while, for the future what you want to see happening.'

Mrs H: 'I would like to get out and about a wee bit, I'm hoping that I'm able to.' Above all though she insisted that she would not under any circumstances move to a nursing home after the suggestion was made by a hospital consultant.

Mrs H: 'I said "I'm going home" I said "you're not putting me into any home" and I took an instant dislike to him.' 
Over the following months, Mrs Howie was admitted to hospital where she stayed for one month. Here she looked visibly distressed, sat on the edge of her seat and eyed the comings and goings. She was now fearful of trying to walk in case she fell and was reluctant then to undergo physiotherapy. Her voiced insistence that she would not go into a nursing home had become a pleading request.

Mrs H: 'They can't make me can they?'

Hazel felt there was no option for Mrs Howie but to move to a home. Knowing her mother's resistance, she could not bear to be burdened with the responsibility for the decision. Thus following a further stay of 3 months in another hospital for ultimately unsuccessful rehabilitation, the doctors informed Mrs Howie that a nursing home was her only option. Once in the nursing home Mrs Howie was like a different person. She had a flattened affect and was totally uninterested in others. She would not socialise with others in the nursing home claiming they were all doo-lally or staring at the TV. Even the man in the neighbouring room who she knew had no cognitive impairment was considered a nuisance. Mrs Howie insisted this was not her home and began refusing to eat, complaining about the food but also rejecting offerings of her favourite brought in by her family. For her this was the end of the line.

Mrs H: 'I didn't think l'd live to this age to finish up like this.'

She felt demeaned by the degree of care that she required and the focus on physical tasks.

Mrs H: 'They just come in get you on the commode get you cleaned up and get you off back to your bed'.

Mrs Howie felt forgotten and lost in the home and told me how she spent her days.

Mrs H: 'looking out the window watching the birds and listening for buses.' 
She spoke about her world in terms of escape, yearning but not hoping, for the freedom to be able to leave the building and come and go as she pleased.

Mrs H: 'Oh, well I would love to be able to get out and walk about. I wouldn't worry staying in here if I could walk out that door and get a bus, have a wee wander, get a bus back again.'

She missed her old neighbour terribly. Since the care home was now an insurmountable journey for him, involving 2 buses and some walking, he had stopped phoning her. Mrs Howie did understand that she had no other option but to move to a nursing home, but it was clear that she had not wanted it as she expressed the decision in a defeatist manner that was tellingly devoid of any personal pronouns.

\section{Mrs H: 'Just looked at it and accepted it.'}

After about 4 weeks Mrs Howie became weak and listless and was admitted to hospital. She was discharged the next day having been told by a doctor that they could find no clear or treatable cause for her malaise. On arrival back in the nursing home and to everyone's great surprise Mrs Howie had announced joyfully 'I'm home'.

Hazel: And we got back and as they were, the strange thing was, as we were going down that long corridor, just as we turned the corner, there's two or three seats where people sit ( $\mathrm{mm} \mathrm{mhm}$ ) and there was a couple of people sitting there, the one that used to annoy mum from day one cause she always sat there, and mum waved to them and she said I'm back, I'm home, I'm back.

Mrs Howie then asked to see the man from the next room that she had previously only complained about. He came through, held her hand and they talked quietly for some time. She died some hours later. 
Mrs Howie's sense of autonomy gradually ebbed away as her initial refusal to go to a nursing home changed to a pleading resistance to finally conceding. While she seemed willing to consider adapting to the sheltered housing, she could not live with the nursing home and viewed her life as one no longer worth living. It may be that her decision to stop eating was purposeful or a physical sequela of her depressive symptoms but either way represented profound unhappiness. Furthermore, given her years of living with diabetes and the subsequent influence of food on her health she must have been aware of the impact of a restricted diet which was likely to have hastened her death. The one thing that she feared most came to fruition and was a loss that took away the final meaning and purpose for her.

Hazel: "I think the minute she actually ended up having to admit that em the nursing home was going to be her only alternative I think she just turned off the taps.'

While spending some of her final hours being taken to and from hospital seems undesirable it counter-intuitively appeared to have offered solace. It was in hearing from the hospital doctor that there was no definable cause for her weakness and malaise that I believe allowed her to recognise that what was happening was her death. She finally knew that she would escape her confines and thus was able to find peace. Mrs Howie 'gave up' as Seale points out, 'human agency plays a part in deciding whether to enter the dying role' (Seale, 1998: p48). Her existential death was the final loss after which she simply waited until death of the body closed her story. After her death her daughter summed up.

Hazel: 'I think, personally, I think she would have liked to have passed on nice, peacefully, quietly in her own four walls which would have been her flat not even the sheltered housing.'

\section{Bringing the narratives together}


The form of the story told by Mrs Brown was of a stable 'core' narrative (Bury, 2001). Despite the losses that were experienced she managed to retain her sense of belonging in the world. She had moved beyond the evaluative dimension of where she was in her life by avoiding selfblame, as she was not questioning why she was the way she now was. The potential to feel like she was a 'burden' on her daughter, meaning the capacity to engage in reciprocating a degree of care outweighed by the need to be cared for (Bury, 2001), was minimised through offering a degree of reciprocity or a level of self-care that buffered the sense of total dependence.

George's story initially reflected a similar stable 'core' narrative that differed in that it became regressive. There was a tension between societal norms of self-reliance with the lived experience of increasing dependence. If 'coping' refers to aspects of how people maintain some sense of worth in the face of intrusive symptoms (Bury (1991) cited in Charmaz, 1995: p657) then conveying any sense of not 'coping' would affect self-esteem and thus compromise self-worth. Increasing dependence strained the capacity to engage in meaningful reciprocal relationships with others, engendering burgeoning fears of being a burden on others and an altered social identity.

George struggled with what exactly he was trying to incorporate, resisting physical decline although without the certainty of what his resistance was against. Either a level of confusion over 'why,' or an unwillingness to incorporate an ageing or frail body as a tangible 'it' left only a level of self-blame. What is dignified in fighting cancer is equally undignified in resisting frailty. These 'struggling' stories outline the disparity in public narratives of life- threatening conditions. Where cancer invokes an imperative to battle the invading entity, frailty is equated to ageing with a dominant imperative to accept with grace. Resisting cancer is 
deemed dignified and strong, yet strength and dignity at the end of life in frailty are found in conceding. Resisting the frail existence is simply regarded as stubbornness.

Mrs Howie's story was, in contrast to the others a tragic 'core' narrative of becoming overwhelmed by losses (Bury, 2001). The story evoked a particular societal narrative of the courageous battle against ill health and potentially feared end point, although without the heroic undertones of a cancer sufferer. However, such battles are publicly located and socially supported. If those closest no longer support the battle, then can it be maintained? Mrs Howie was forced to concede to what she had struggled to avoid. Although the responsibility for making the decision to enter this final stage was attributed to a doctor there was a crucial tipping point. Mrs Howie's daughter had reached the moment where the resources to cope with what she faced were exhausted or simply unavailable as she told of her struggle with the burden of responsibility, of the ever-present uncertainty of being 'on call'. It was then that Mrs Howie could no longer sustain her position. Mrs Howie's account illustrates how once the battle was lost, there was no way to reconstruct her narrative and she was left desolate, facing an untold and undefined future. Yet once it became clear to her that her death was imminent, and her story could end, she seemed to rekindle the light of her old self momentarily, and perhaps briefly reconstructing the self before her life was finally gone. In the end Mrs Howie experienced grand losses and many deaths, the social, the self and the existential before she died physically.

\section{Discussion}




\section{Narrative and biography}

The experience of living with frailty involves increasing losses which disrupt, and progressively restrict, the everyday lives of older people resonating with the concept of biographical disruption in chronic illness (Bury, 1982). This involves disruption of the takenfor-granted aspects of the physical body, of daily life and relationships with the self and others, where the person experiences a shift from their normal expected life trajectory that undermines self-identity.

Yet frailty is both disruptive and at the same time biographically anticipated as the older people in this study varyingly utilised age-related degeneration to explain their circumstances. The stable narratives resonate with those of older people with osteoarthritis who reportedly described their symptoms as a normal and inevitable consequence of ageing but, at the same time, as abnormal in the level of disruption to their daily lives (Sanders et al., 2002). How people adapt to disruptions has been described in the theory of narrative reconstruction (Williams, 1984) in the accounts of those with a longstanding experience of rheumatoid arthritis. Williams explains that people utilise strategies that create stability and cohesion following a disruptive event "linking and interpreting different aspects of biography in order to realign present and past and self and society" (Williams, 1984: p197). When living with increasing frailty, however, older people are frequently coping with multiple conditions and symptoms as opposed to one illness or event. They live with wide ranging disruptions to their day to day life from mobility difficulties to breathlessness, incontinence or difficulties in eating due to poor strength, fine motor manipulation or fatigue. Such experiences make attempts to create stability and cohesion and create a sense of connection to the past self much more challenging. 
Frail older participants, whose stories remained stable also voiced some level of adequate explanation for their circumstances. They told coherent stories that may be considered as vital to resilient ageing (Randall, 2012). Those who could point to a clear starting point or cause for their difficulties could hold on to this explanation in conjunction with a belief in normative processes of ageing, allowing their situations to continue to make sense. This may be because they identified a single factor to attribute their decline. They were thus able to live in the present and accept their circumstances having adapted to a way of living that fitted their life story. In contrast, it was those who had been the most physically fit prior to their existing condition that seemed to struggle with adapting to a new self. They were less able to accept their limitation, a difficulty described by Frost et al (2017). Perhaps the psychological recourse to prior fit and active selves functioned as a defensive strategy when frailty, with its multiple disruptions and co-morbidities, threatened to engulf the previously held sense of self. Where narratives took a regressive form and became unbalanced the older people described a more ambiguous and insecure position. There is a tension at play here between normative expectations of ageing bodies and wishing for a quick end that avoids a protracted or lingering death. As Kellehear explains, 'there is a widespread fantasy that one might reach 80 or 90 years old in good health and die in one's sleep. But the epidemiological reality is rather different' (Kellehear, 2007: p232). Certainly the frail older participants in this study appeared to have expected, or wishfully anticipated, to 'drop dead' rather than linger on with increasing incapacity and dependence. There was little openness around discussion of death and dying reflecting the findings of Clarke and Seymour (Clarke and Seymour, 2010). Further, the very expected nature of frailty is double edged as the apparent ordinariness of suffering in ageing bodies renders it invisible. It is expected, non-shocking and thus 
unremarkable. The frail older participants offered comparisons between their own circumstances and those of other older people that functioned to distance themselves from those worse off, but also as a recognisable, culturally acceptable strategy to prove oneself as uncomplaining and stoical. Such social positioning strategies used by older people can illuminate the tensions of growing older and the desire to resist the normative assumptions frequently associated with old age as well as offer reassurance by making selective comparisons to those in what may be considered worse situations (Allen and Wiles, 2013, Jones, 2006). In fact older people can consider frailty as a position of despair and defeat (Pickard, 2018).

Making sense of causative factors is central to the process of narrative reconstruction, yet was an area of struggle in the narrative accounts that were unbalanced. The older people expected and knew that old age comes with infirmity and that frailty is ultimately likely, yet somehow did not expect it when it came. Williams' participants were long term 'sufferers' of rheumatoid arthritis whose identity was undermined by their condition and expressed identity with terms like 'this isn't me' (Williams, 1984, Tanner, 2007). In contrast, the older aged participants with osteoarthritis in Sanders et al study seemed to consider their symptoms as normal and integrated into their biographies (Sanders et al., 2002). Frail older participants in this study that were able to make sense of their circumstances by considering old age combined often with another event or illness as cause enough, did not describe biographical insecurities. However, when their narratives became unbalanced and ultimately overwhelmed as difficulties and symptoms increased, the older people became unconvinced about the disruption to their lives and began to question why. Old age no longer seemed enough to account for the degree of disruption that they were experiencing. This may be 
because it is difficult to disentangle illness from the gradually developing and nebulous quality of ageing and frailty and the sheer amount of difficulties that may ensue, such that any degree of demarcation may be impossible.

Sanders describes the process of diagnosis in osteoarthritis as being less clear cut than in other chronic illness thus melding with a degree of expectations of normal ageing. Such distinction is even less clear in frailty which is not named let alone diagnosed. How an illness is categorised can have implications for legitimacy, with frailty falling into the category of 'health problems which are not illnesses' (Cornwell, 1984) with the attendant moral imperative to stoical acceptance. Expanding from this it seems that having a clear reason for incapacitates allows older people to distance the self from the situation and thus adapt better to their new circumstances. As Bury explains "the separation of disease from self is a powerful cultural resource", "To be able to hold the disease at a distance, as it were, assists the claim that one is a victim of external forces. To do anything less is to accept fully the burden of responsibility." (Bury, 1982: p172).

Williams has further argued that there may be illnesses that are biographically embedded in the individual (Williams, 2000). In a study of people who had experienced stroke Pound found that those who had previously experienced illness, and who questioned their assumptions about their bodies and their future, did not describe the same sense of disruption to their biographies as those who had not (Pound et al., 1998). The account of Mrs Brown would be consistent with this notion. We had struggled to understand why she seemed almost uniquely at peace with her physical limitations and suffering. Yet, we began to realise that her identity was for many years incorporated as that of a person with a chronic illness when she 
told me that she had lived with a diagnosis of osteoarthritis for 40 years. Mrs Brown had a clear causative ailment that was integrated into her life since early middle age. She did not, now, need to find a new sense of self having incorporated disability and bodily discomfort into her self-identity for many years.

It may seem surprising that the disruptions of an ageing body could be regarded with an element of confusion as to the cause or even surprise. However, that older people can actively resist the frail identity (Warmoth et al., 2016) is unsurprising in today's society with a pervasive rhetoric of successful aging (Rowe and Kahn, 1997, Lloyd et al., 2014a). Ageing 'successfully' is predicated on the ideals of youth and the imperative to retain independence meaning older people are confronted with the image of failure should they not live up to such ideals (Lloyd et al., 2014b). Those that have no clear reason for being frail are left with no alternative but to blame themselves. Perhaps this is an unwelcome effect of the dominant image of the active older person who reaches retirement in full physical health. This image does not fit with that of the declining frail older person. Furthermore, many of the participants had reached the age they were at, at least in part, by adopting the health seeking lifestyles of modern-day health promotion policy. None currently smoked, and both women and men were eager to point out the degree of physical activity that they had undertaken throughout their lives. Others pointed to exercising the 'mind' utilising the 'use it or lose it' theory of averting dementia in later life. It is not surprising within this context that they could feel cheated of their physical robustness especially when media images portray 'super fit octogenarians'. As Gilleard and Higgs assert "frailty plays an important role in re-organizing later life along the dualism of the third and fourth age where the agency and health of the former are contrasted with the loss of those capacities in the latter." (Gilleard and Higgs, 
2010: p5). Despite the cognitive acceptance that their bodies were declining due to the combined effects of old age and accumulating health issues it was not emotionally accepted in the regressive narratives without a clear reason.

\section{Strengths and limitations of the study.}

This study is novel in its aim of looking at how the stories of frail older people can change over time and the manner in which they do so, as well as identifying common forms of narrative that underlie the stories. This was facilitated by serial interviews and interim phone contact that allowed change to be captured as it occurred.

Rigour was achieved by including the perspectives of family members and professionals where possible to give a broad context and detail to the accounts. All the interviews were carried out by the same researcher and ongoing analysis was discussed with the research team regularly. The study also focuses on frail older people with minimal or no cognitive impairment living in the community, who have not received the same research attention as those living in care homes. A weakness of the method is that is that it does not account for frail older people who may not have an informal carer or who have dementia. Additionally, the small number of participants limit extrapolation to wider contexts. It should be noted that the story types presented are analytical constructs that serve as illustrative possibilities that may help to understand or frame the experiences of older people rather than being distinct categories that are representative or predictive.

\section{Conclusion and implications}


The personal narratives that frail older people use to make sense of their lives have similarities and differences with those living with distinct illnesses. Their experiences, however, may relate to a great many people living with various co-morbid conditions - a situation that is increasingly common with increasing age. A significant issue is the sense of self-blame that can occur as one cannot place the cause for disability or infirmity on to a single cause. This makes it difficult to distance reduced well-being from the self to an external physical factor such as a specific illness. Adapting to life and coping with frailty cannot simply be reduced to a single process but is specific to individual factors but also to social circumstances as well as the degree of physical difficulties. By considering these narrative types, those working with frail older people can identify triggers for holistic assessment and inform patient-centred advance care planning to better support older people as they face changes and transitions. The narratives highlight the distress that can emerge when personal stories no longer make sense within a broader life context, and when existential or psychological support might help maintain well-being, as well as highlight where self-blame or fear could impact on an older person's well-being. Attending to personal narratives of older people could potentially enhance the resilience of older people through encouraging them 'to move past their initial formulations of "the story of my life" ' and empower the capacity to 'delve more extensively into our stories and reflect on them more fully-especially those troubling episodes that resist coherent resolution and yet, by working them through, can enhance our capacity for resilience.' (Randall et al., 2015 p:160)

- Approval for the study was granted by the Lothian Research Ethics Committee (Reference Number 09/S1101/6) and by NHS governance systems.

- The study was funded by the Economics and Social Research Council 
- Contributors: AL carried out the data collection and analysis. AL prepared the initial manuscript to which BM and EH contributed. MK and SM were academic supervisors for the study.

- Conflict of interests: There are no conflicts of interest in this study.

\section{References}

ALLEN, R. E. and WILES, J. L. (2013) The utility of positioning theory to the study of ageing: Examples from research with childless older people. Journal of Aging Studies, 27, 175-187.

BINGLEY, A. F., MCDERMOTT, E., THOMAS, C., PAYNE, S., SEYMOUR, J. and CLARK, D. (2006) Making sense of dying: a review of narratives written since 1950 by people facing death from cancer and other diseases. Palliative Medicine, 20, 183-195.

BURY, M. (1982) Chronic illness as biographical disruption. Sociology of health and illness, 4, 167182.

BURY, M. (2001) Illness narratives: fact or fiction? Sociology of health and illness, 23, 263-285.

CHARMAZ, K. (1995) The body, identity, and self. The Sociological Quarterly, 36, 657-680.

CLARKE, A. and SEYMOUR, J. (2010) "At the foot of a very long ladder": Discussing the end of life with older people and informal caregivers. Journal of pain and symptom management, $\mathbf{4 0 ,}$ 857-869.

CLEGG, A., YOUNG, J., ILIFFE, S., RIKKERT, M. O. and ROCKWOOD, K. (2013) Frailty in elderly people. The Lancet, 381, 752-762.

CORNWELL, J. (1984) Hard-earned lives: accounts of health and illness from East London, Routledge Kegan and Paul.

CROSSLEY, M. L. (1999) Making sense of HIV infection: Discourse and adaptation to life with a longterm HIV positive diagnosis. Health:, 3, 95-120. 
DE MEDEIROS, K. (2013) Narrative gerontology in research and practice, Springer Publishing Company.

DODGE, R., DALY, A. P., HUYTON, J. and SANDERS, L. D. (2012) The challenge of defining wellbeing. International journal of wellbeing, 2, 3, 222-235

ELLIOT, J. (2005) Using narrative in social research: Qualitative and quantitative perspectives. London: Sage Publications.

FOLSTEIN, M. F., FOLSTEIN, S. E. and MCHUGH, P. R. (1975) “Mini-mental state": a practical method for grading the cognitive state of patients for the clinician. Journal of psychiatric research, 12, 189-198.

FRANK, A. W. (2013) The wounded storyteller: Body, illness, and ethics, University of Chicago Press. FROST, R., KHARICHA, K., JOVICIC, A., LILJAS, A.E., ILLIFFE, S., MANTHORPE, J., GARDNER, B., AVGERINOU, C., GOODMAN, C., DRENNAN, V.M. and WALTERS, K., (2018) Identifying acceptable components for home-based health promotion services for older people with mild frailty: A qualitative study. Health \& social care in the community, 26, 3, 393-403.

GILLEARD, C. and HIGGS, P. (2010) Aging without agency: Theorizing the fourth age. Aging and Mental Health, 14, 121-128.

JONES, R. L. (2006) 'Older people'talking as if they are not older people: Positioning theory as an explanation. Journal of Aging Studies, 20, 79-91.

KAUFMAN, S. R. (1994) The social construction of frailty: an anthropological perspective. Journal of Aging Studies, 8, 45-58.

KELLEHEAR, A. (2007) A social history of dying. Cambridge, 21, 36.

LAWTON, J. 2002. The dying process: patients' experiences of palliative care, Routledge.

LLOYD, A., KENDALL, M., STARR, J. M. and MURRAY, S. A. (2016) Physical, social, psychological and existential trajectories of loss and adaptation towards the end of life for older people living with frailty: a serial interview study. BMC geriatrics, 16, 176. 
LLOYD, L., CALNAN, M., CAMERON, A., SEYMOUR, J. and SMITH, R. (2014a) Identity in the fourth age: perseverance, adaptation and maintaining dignity. Ageing and Society, 34, 1-19.

LLOYD, L., CALNAN, M., CAMERON, A., SEYMOUR, J., SMITH, R. and WHITE, K. (2011) Maintaining dignity in later life: a longitudinal qualitative study of older people's experiences of support and care. University of Bristol. Bristol.

LLOYD, L. and CAMERON, A. (2005) Significant life events: Developing knowledge for care at the end of life in old age. Journal of Integrated Care, 13, 34-39.

LLOYD, L., TANNER, D., MILNE, A., RAY, M., RICHARDS, S., SULLIVAN, M. P., BEECH, C. and PHILLIPS, J. (2014b) Look after yourself: active ageing, individual responsibility and the decline of social work with older people in the UK. European Journal of Social Work, 17, 322-335.

LLLOYD-WILLIAMS, M., KENNEDY, V., SIXSMITH, A. and SIXSMITH, J., (2007) The end of life: a qualitative study of the perceptions of people over the age of 80 on issues surrounding death and dying. Journal of pain and symptom management, 34, 1,60-66.

MURRAY, M. and CHAMBERLAIN, K. (1999) Qualitative health psychology: Theories and methods, Sage.

MURRAY, S. A., BOYD, K., KENDALL, M., WORTH, A., BENTON, T. F. and CLAUSEN, H. (2002) Dying of lung cancer or cardiac failure: prospective qualitative interview study of patients and their carers in the community. BMJ: British Medical Journal 325, 929

NICHOLSON, C., MEYER, J., FLATLEY, M., HOLMAN, C. and LOWTON, K. (2012) Living on the margin: understanding the experience of living and dying with frailty in old age. Social science and medicine, 75, 1426-1432.

ONS (2006). General Household survey 2006 Office of National Statistics.

https://webarchive.nationalarchives.gov.uk/20081014161030/http://www.statistics.gov.uk/ StatBase/Product.asp?vlnk=5756

PICKARD, S. (2018) Health, illness and frailty in old age: a phenomenological exploration. Journal of aging studies, 47, 24-31. 
POUND, P., GOMPERTZ, P. and EBRAHIM, S. (1998) Illness in the context of older age: the case of stroke. Sociology of Health and IIIness, 20, 489-506.

PUTS, M. T., SHEKARY, N., WIDDERSHOVEN, G., HELDENS, J. and DEEG, D. J. (2009) The meaning of frailty according to Dutch older frail and non-frail persons. Journal of Aging Studies, 23, 258266.

RANDALL, W., BALDWIN, C., MCKENZIE-MOHR, S., MCKIM, E. and FURLONG, D. (2015) Narrative and resilience: A comparative analysis of how older adults story their lives. Journal of aging studies, 34, 155-161.

RANDALL, W. L. (2012) The importance of being ironic: Narrative openness and personal resilience in later life. The Gerontologist, 53, 9-16.

ROCKWOOD, K., SONG, X., MACKNIGHT, C., BERGMAN, H., HOGAN, D. B., MCDOWELL, I., MITNITSKI, A. (2005) A global clinical measure of fitness and frailty in elderly people. Canadian Medical Association Journal, 173, 489-495.

ROWE, J. W. and KAHN, R. L. (1997) Successful aging. The gerontologist, 37, 433-440.

SANDERS, C., DONOVAN, J. and DIEPPE, P. (2002) The significance and consequences of having painful and disabled joints in older age: co-existing accounts of normal and disrupted biographies. Sociology of health and illness, 24, 227-253.

SEALE, C. (1998) Constructing death: The sociology of dying and bereavement, Cambridge University Press.

TANNER, D. (2007) Starting with lives: Supporting older people's strategies and ways of coping. Journal of Social Work, 7, 7-30.

WARMOTH, K., LANG, I. A., PHOENIX, C., ABRAHAM, C., ANDREW, M. K., HUBBARD, R. E. and TARRANT, M. (2016) 'Thinking you're old and frail': a qualitative study of frailty in older adults. Ageing and Society, 36, 1483-1500.

WILLIAMS, G. (1984) The genesis of chronic illness: narrative re-construction. Sociology of health and illness, 6, 175-200. 
WILLIAMS, S. (2000) Chronic illness as biographical disruption or biographical disruption as chronic illness? Reflections on a core concept. Sociology of Health and IIIness, 22, 40-67.

ZHENG, L., FINUCANE, A., OXENHAM, D., MCLOUGHLIN, P., MCCUTCHEON, H. and MURRAY, S. (2013) How good is primary care at identifying patients who need palliative care? A mixedmethods study. European Journal of Palliative Care, 20, 216-222.

Correspondence may be addressed to Dr Anna Lloyd, email:

alloyd@stcolumbashospice.org.uk 